\title{
Effects of Thermal Curing on the Structure of Polyimide Film
}

\author{
Sang-Kyung KIM, Hee-Tak KIM, and Jung-Ki PARK ${ }^{\dagger}$ \\ Department of Chemical Engineering, Korea Advanced Institute of Science and Technology, \\ 373-1, Yusung-gu, Kusung-dong, Daejon 305-701, Korea
}

(Received August 15, 1997)

\begin{abstract}
The effects of thermal curing method on degree of imidization, molecular orientation, and chain ordering of the 4,4-oxydiphenylene pyromellitimide (PMDA-ODA) were investigated. Three different thermal curing methods were chosen in this study; two casts of polyamic acid on silicon wafer were isothermally cured at $200^{\circ} \mathrm{C}$ for $3 \mathrm{~h}(\mathrm{I}-200)$ and $300^{\circ} \mathrm{C}$ for $3 \mathrm{~h}$ (I-300) respectively, and the other one was cured in step manner (S-300): $100^{\circ} \mathrm{C}$ for $1 \mathrm{~h}, 200^{\circ} \mathrm{C}$ for $1 \mathrm{~h}$, and finally $300^{\circ} \mathrm{C}$ for $1 \mathrm{~h}$. The degree of imidization was highest in the I-300 and lowest in the S-300, demonstrating that the amount of solvent and degree of imidization at each stage of the curing cycles significantly affect the final degree of imidization. The degree of in-plane orientation was found highest for the S-300 and lowest for the I-300. This suggests that the in-plane orientation decreases with increase of the chain immobilization. This chain ordering was found to be easily induced for the I-300 among the three cured films. In the I-300, the chains in the film are sparsely packed and ordering by the diffusion of polymer chians occurs most easily.

KEY WORDS 4,4-Oxydiphenylene Pyromellitimide / Degree of Imidization / Molecular Orientation / Chain Ordering /
\end{abstract}

In recent years, much attention has been directed to aromatic polyimide films, widely used as high-temperature insulators and dielectric coatings, adhesives, matrices, and alignment layer films for liquid crystal display. ${ }^{1,2}$ The traditional synthetic route for these materials is two steps, the synthesis of poly(amic acid) (PAA) and subsequent thermal or chemical imidization (curing) of the PAA. ${ }^{1}$ In preparation of the polyimide films, thermal imidization is generally used as the second step. Thermal imidization involves the simultaneous loss of solvent, cyclization of amic acid group to form imide, and both intra- and inter-molecular structure evolution. 3,7-12 Regulation of the conditions on thermal imidization provides a wide spectrum of properties. Thus, understanding the effects of thermal curing method on the structure of the resulting polyimide film is very important to control the microstructure of the polyimide formed and to ensure final properties. However, a comparison of the degree of imidization, molecular orientation, and chain ordering among the polyimide films prepared by thermally different curring methods has not been made.

This article studies the effects of thermal curing method on the structure of the polyimide films interfaced with silicon substrate. Three different curing methods were taken as follows; (i) isothermal curing at $200^{\circ} \mathrm{C}$ for $3 \mathrm{~h}$ (I-200), (ii) isothermal curing at $300^{\circ} \mathrm{C}$ for $3 \mathrm{~h}$ (I-300), and (iii) step curing (S-300) which consists of three steps: isothermal heating at $100^{\circ} \mathrm{C}$ for $1 \mathrm{~h}$ followed by isothermal heating at $200^{\circ} \mathrm{C}$ for $1 \mathrm{~h}$, and then isothermal heating at $300^{\circ} \mathrm{C}$ for $1 \mathrm{~h}$.

\section{EXPERIMENTAL}

\section{Materials}

Pyralin (Du Pont), a mixture of polyamic acid $\left(4,4^{\prime}-\right.$ oxydiphenylene pyromellitamic acid), 1-methyl-2-pyrro-

\footnotetext{
${ }^{\dagger}$ To whom all correspondence should be addressed.
}

lidone (NMP), and petroleum ether, was poured into excess methanol to precipitate the polyamic acid. The precipitates were washed with methanol several times and dried at $60^{\circ} \mathrm{C}$ under vacuum for $12 \mathrm{~h}$, and then used to prepare $20 \mathrm{wt} \%$ NMP solution. NMP was purchased from Aldrich and used as received.

\section{Film Preparations}

PAA solution of $20 \%$ by weight in NMP was spincast on the silicon wafer at $1000 \mathrm{rpm}$. After spinning, the casts were prebaked at $70^{\circ} \mathrm{C}$ for $30 \mathrm{~min}$ and the initial solvent content of the PAA films was measured. The PAA films were thermally cured using the temperature controllable FT-IR kit under atmospheric conditions.

\section{FT-IR Measurements}

The FT-IR spectra were obtained using a Bomem 102 spectrometer at a resolution of $4 \mathrm{~cm}^{-1}$ and 20 scans were averaged. During the curing of the PAA films, the spectra were taken every three minutes to investigate changes of the spectra with time.

\section{Differential Scanning Calorimetry Measurements}

Differential scanning calorimetry (DSC) measurements for the polyimide films peeled from the substrate were conducted using the Du Pont Instrument 910 differential scanning calorimeter from $30^{\circ} \mathrm{C}$ to $450^{\circ} \mathrm{C}$ at a heating rate of $10^{\circ} \mathrm{C} \mathrm{min}^{-1}$ under nitrogen.

\section{RESULTS AND DISCUSSION}

\section{Effects of Curing on the Degree of Imidization}

The degree of imidization of the imidized polyamic acid films represents the percent conversion of the amic acid group into imide and is closely related to the final properties of the imidized polyamic acid films. Imidization proceeds faster in the presence of amide solvents, due to the plasticizing effect of the solvent. ${ }^{18}$ Due to 


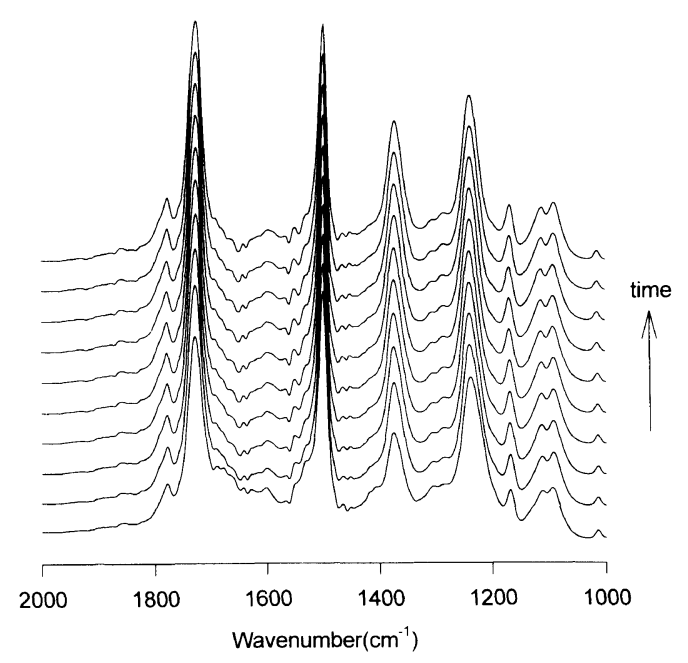

Figure 1. FT-IR spectra of the imidized polyamic acid film taken at intervals of $3 \mathrm{~min}$ during curing at $200^{\circ} \mathrm{C}$ for $30 \mathrm{~min}$.

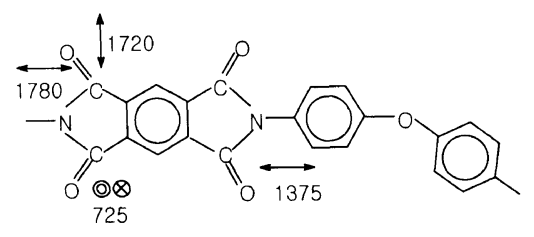

Figure 2. Directions of the transitional moments and wavenumbers $\left(\mathrm{cm}^{-1}\right)$ of molecular vibrations of PMDA-ODA.

the important role of solvent on thermal imidization, there is a need to quantify solvent content as well as degree of imidization. This work determined the residual solvent content and degree of imidization of the film by the FT-IR spectroscopic technique.

Changes in FT-IR spectra of the imidized polyamic acid film during the curing at $200^{\circ} \mathrm{C}$ are given in Figure 1. The bands at 1780 and $1720 \mathrm{~cm}^{-1}$ (symmetric and asymmetric stretching of carbonyl groups), $1375 \mathrm{~cm}^{-1}$ (C-N stretching) and $725 \mathrm{~cm}^{-1}$ (imide ring deformation) generally characterize an imide ring. ${ }^{10}$ The intensities of the three peaks, $1780 \mathrm{~cm}^{-1}, 1720 \mathrm{~cm}^{-1}$, and $1375 \mathrm{~cm}^{-1}$, increased with imidization time. Figure 2 shows the directions of transitions and wavenumbers of the molecular vibrations of the groups in the imide ring. The band at $1375 \mathrm{~cm}^{-1}$ was least influenced by overlapping with other bands, ${ }^{14}$ and thus was selected for quantifying the degree of imidization. To exclude the effects of film thickness and chain orientation on the degree of imidization, the aromatic band at $1500 \mathrm{~cm}^{-1}$ is usually selected as the internal standard. ${ }^{13}$ The band at $1500 \mathrm{~cm}^{-1}$ which has the same transition moment direction as the imide band at $1375 \mathrm{~cm}^{-1}$ is nearly unchanged with imidization. ${ }^{10}$ To determine the degree of imidization, the ratio of the area of the imide band at $1375 \mathrm{~cm}^{-1}$ to the area of the internal standard was first obtained. This ratio was then referenced to the ratio obtained on a fully cured film imidized at $350^{\circ} \mathrm{C}$ for $1 \mathrm{~h}$. Heating at $\geq 300^{\circ} \mathrm{C}$ for at least $0.5 \mathrm{~h}$ is normally required to obtain the reference sample, which is considered to be $100 \%$ imidized. ${ }^{10,18-20}$ The equation for calculating the percent degree of imidization is, ${ }^{5}$ :

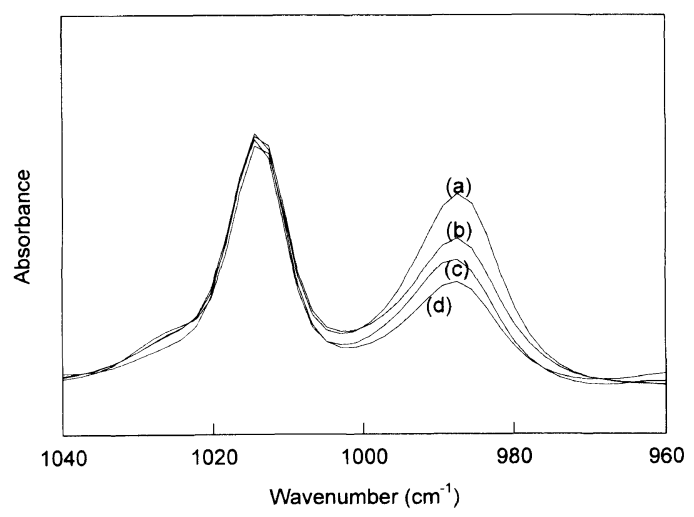

Figure 3. FT-IR spectra of polyamic acid films with various solvent contents: Number of NMP molecules/amic acid unit =(a) 2.2; (b) 1.7; (c) 1.6 ; (d) 1.3 .

$$
D I(\%)=\frac{\left(A_{1375} / A_{1500}\right)_{\text {sample }}}{\left(A_{1375} / A_{1500}\right)_{\text {fully imidized one }}} \times 100
$$

To quantify the absolute amount of solvent in the film during and after curing, a new simple method is proposed in this article. NMR is a useful tool to quantify the absolute amount of selected material. However the partially or fully cured film is insoluble in most solvents, causing difficulty of NMR. In case of FT-IR to check the contained material, it is not necessary to find the proper solvent though FT-IR cannot analyze material quantitatively but qualitatively. Therefore, calibration equation, which transforms the qualitative FT-IR information to absolute quantity of the contained solvent in the polyimide films, was derived using the PAA as a reference material.

Figure 3 shows the FT-IR spectra of the polyamic acid films at various solvnet contents. The spin-coated films were prebaked under different conditions to obtain PAA films containing different amounts of residual solvent. The height of the solvent (NMR) band at $985 \mathrm{~cm}^{-1}$ normalized to the height of the polyamic acid band at $1015 \mathrm{~cm}^{-1}$ (skeleton vibration of benzene) was taken as the relative amount of residual solvent in the PAA film. ${ }^{15}$ The PAA films were dissolved in dimethyl sulfoxide- $d_{6}$ to obtain ${ }^{1} \mathrm{H}$ NMR spectra from which the absolute amount of the solvent in PAA film was quantified. The ratio of the height of the solvent peak to that of the PAA peak from the IR spectra is related to the absolute quantity of the residual solvent in the film determined from NMR. The equation which correlates the ratio obtained from IR peaks with the solvent content determined from NMR methods was found to be,

$$
y=5.541 x-5.257 x^{2}+1.755 x^{3}
$$

where $x$ is the ratio of the IR peaks and $y$ is the number of NMP molecules per amic acid unit. By this equation, we could investigate changes of solvent content in the PAA film during imidization by monitoring changes of the height of the solvent peak in the IR spectra with imidization time.

Figure 4 shows the changes of the percent degree of imidization with curing time for the three differently cured films. I-300 showed the highest degree of imidization, $100 \%$. The degree of imidization for I-200 was slightly lower than that of $\mathrm{I}-300$ while S-300 revealed 


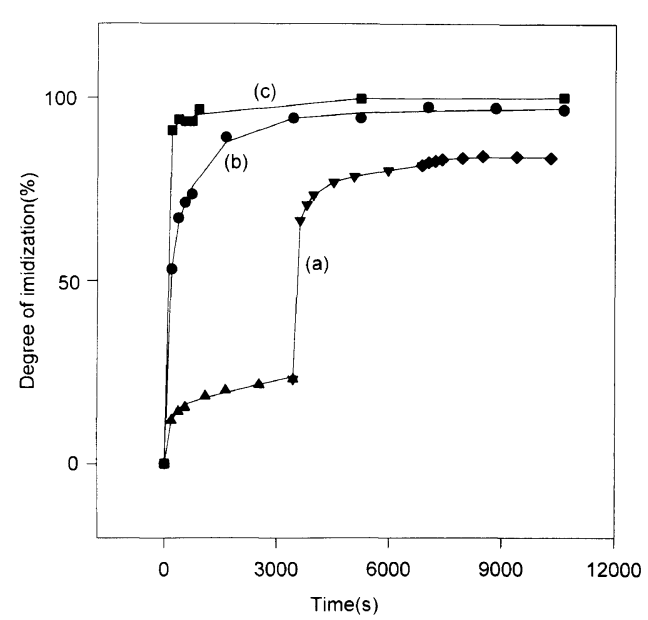

Figure 4. Degree of imidization with curing time for (a) step curing (at $100^{\circ} \mathrm{C}$ for $1 \mathrm{~h}(\boldsymbol{\Delta})$, at $200^{\circ} \mathrm{C}$ for $1 \mathrm{~h}(\boldsymbol{\nabla})$, then at $300^{\circ} \mathrm{C}$ for $1 \mathrm{~h}(\bullet)$ ); (b) curing at $200^{\circ} \mathrm{C}$ for $3 \mathrm{~h}(\boldsymbol{O})$; (c) curing at $300^{\circ} \mathrm{C}$ for $3 \mathrm{~h}(\boldsymbol{\square})$.

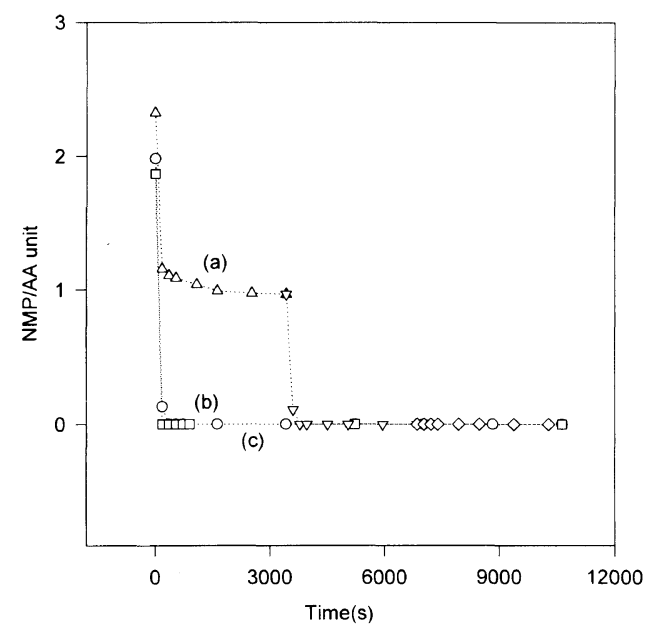

Figure 5. Amount of residual solvent with curing time for (a) the step curing (at $100^{\circ} \mathrm{C}$ for $1 \mathrm{~h}(\triangle)$, at $200^{\circ} \mathrm{C}$ for $1 \mathrm{~h}(\nabla)$, then at $300^{\circ} \mathrm{C}$ for $1 \mathrm{~h}(\diamond))$; (b) curing at $200^{\circ} \mathrm{C}$ for $3 \mathrm{~h}(\mathrm{O})$; (c) curing at $300^{\circ} \mathrm{C}$ for $3 \mathrm{~h}(\square)$.

the lowest degree of imidization. It is notable that even though the final imidization temperature for the S-300 and the I-300 was the same, there were significant differences in the degree of imidization in the two curing methods. Comparing the degrees of imidization of the $\mathrm{I}-200$ and second stage (curing at $200^{\circ} \mathrm{C}$ for $1 \mathrm{~h}$ ) of the $\mathrm{S}-300$, the step cured film was found to show significantly lower conversion.

Figure 5 shows change of the residual solvent content with curing time for the three differently cured films. At the start of the curing, the solvent content was about 2 NMP molecules per amic acid unit for all cured films. For the step-cured one, 1 NMP molecule per amic acid group remained after the first stage imidization (isothermal curing at $100^{\circ} \mathrm{C}$ ). The solvents were rapidly evaporated when the PAA films were isothermally heated at $200^{\circ} \mathrm{C}$ or $300^{\circ} \mathrm{C}$. The amount of solvent which forms a stable complex with the amic acid unit thus depends on the imidization temperature. At $100^{\circ} \mathrm{C}$, only one NMP molecule can make a stable complex, while at $200^{\circ} \mathrm{C}$ and above, most solvents are decomplexed and evaporated.
The amount of solvent molecules making the stable complex with the amic acid unit, may depend not only on the imidization temperature but the sort of solvent.

When comparing the first $1 \mathrm{~h}$ of I-300 with the last stage of the step curing (S-300), these two stages were noted to have different initial solvent content (2 NMP/ amic acid unit for the I-300 and no NMP for the S$300)$ and different initial degrees of imidization $(0 \%$ for I-300 and 75\% for S-300). The mobility of the reacting medium should thus be much lower in S-300, resulting in profoundly lower conversion of S-300: $98 \%$ increase in the conversion for the isothermal curing at $300^{\circ} \mathrm{C}$ and only $1 \%$ increase for third stage in the step curing. For the first $1 \mathrm{~h}$ of I-200 and second stage (S200 ) of the step curing (S-300), the imidization temperatures were identical but the initial solvent content (2 NMP/amic acid unit for the I-200 and 1 NMP/amic acid unit for the S-200) and initial degree of imidization $(0 \%$ for the I-200 and $23 \%$ for the S-200) were different. Thus, there was large difference in increase of degree of imidization, i.e., $97 \%$ for the isothermal curing and $53 \%$ for the step curing.

These results suggest that the high initial solvent content and the low initial degree of imidization at each stage of curing cycles increase the chain mobility and consequently lead to the high eventual degree of imidization. As far as we are concerned on the degree of imidization, the step curing was found to be inadequate to obtain the high degree of imidization due to the loss of solvent and increase of degree of the imidization induced during curing at the low-temperature stage in the step curing.

\section{Effects of Curing on Molecular Orientation}

Molecular orientation of polyimide film is important for the various properties such as residual stress, optical and dielectric anisotropy. Since the polyimide chain is rigid, chain director tends to be aligned parallel to the substrate, which is referred to as "in-plane orientation." The higher in-plane orientation causes higher optical and dielectric anisotropy.

Iida et $a l .{ }^{6}$ developed a method for the quantitative evaluation of molecular orientation in organic films containing rigid parts using FT-IR spectroscopy. Polyimide has the imide ring as the rigid part, so this method was selected for quantitative evaluation of molecular orientation of the polyimide films. Using the three transitional moments mutually perpendicular to each other $(i, j$, and $k)$, molecular orientation was evaluated quantitatively by the following equations:

$$
\begin{aligned}
\left\langle\cos ^{2} \theta_{i}\right\rangle & =\frac{A_{i} A_{j}^{\text {iso }} A_{k}^{\text {iso }}}{\left(A_{i} A_{j}^{\text {iso }} A_{k}^{\text {iso }}+A_{i}^{\text {iso }} A_{j} A_{k}^{\text {iso }}+A_{i}^{\text {iso }} A_{j}^{\text {iso }} A_{k}\right)} \\
\left\langle\cos ^{2} \theta_{j}\right\rangle & =\frac{A_{i}^{\text {iso }} A_{j} A_{k}^{\text {iso }}}{\left(A_{i} A_{j}^{\text {iso }} A_{k}^{\text {iso }}+A_{i}^{\text {iso }} A_{j} A_{k}^{\text {iso }}+A_{i}^{\text {iso }} A_{j}^{\text {iso }} A_{k}\right)} \\
\left\langle\cos ^{2} \theta_{k}\right\rangle & =\frac{A_{i}^{\text {iso }} A_{j}^{\text {iso }} A_{k}}{\left(A_{i} A_{j}^{\text {iso }} A_{k}^{\text {iso }}+A_{i}^{\text {iso }} A_{j} A_{k}^{\text {iso }}+A_{i}^{\text {iso }} A_{j}^{\text {iso }} A_{k}\right)}
\end{aligned}
$$

where $A$ is the peak intensity, $\theta$ is the angle between transitional moment and field component of IR light, subscript $i, j$, and $k$ mean the peak positions $\left(\mathrm{cm}^{-1}\right)$ of the three transition moments and the superscript iso 
Table I. Orientation of PMDA-ODA film

\begin{tabular}{lccc}
\hline & Step cured & $\begin{array}{c}\text { Isothermally cured } \\
\text { at } 200^{\circ} \mathrm{C}\end{array}$ & $\begin{array}{c}\text { Isothermally cured } \\
\text { at } 300^{\circ} \mathrm{C}\end{array}$ \\
\hline$\left\langle\cos ^{2} \theta_{725}\right\rangle$ & 0.36 & 0.37 & 0.53 \\
$\left\langle\cos ^{2} \theta_{1375}\right\rangle$ & 0.41 & 0.40 & 0.31 \\
$\left\langle\cos ^{2} \theta_{1720}\right\rangle$ & 0.23 & 0.22 & 0.16 \\
\hline
\end{tabular}

(a)
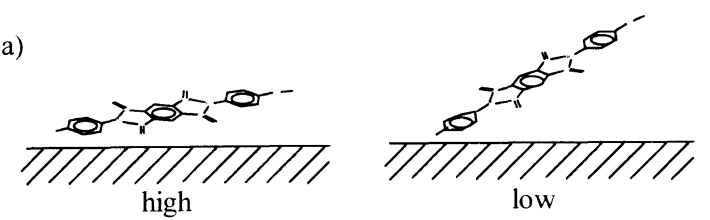

(b)
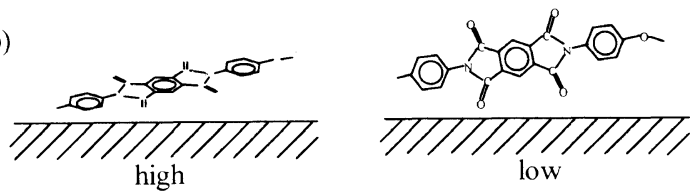

Figure 6. Schematic illustration of molecular orientation: (a) in-plane orientation of the molecule; (b) parallel character of the imide ring to the substrate.

means the peak area for the isotropic case. The peak area of isotropic film was calculated by IR trichroic measurement. ${ }^{16}$ Bands at 725,1720 , and $1375 \mathrm{~cm}^{-1}$ were selected for the three transitional moments mutually perpendicular to each other (Figure 2). From these peaks, orientation of the pyromellitimide ring could be calculated.

Table I shows the values of $\left\langle\cos ^{2} \theta\right\rangle$ of peaks for differently cured polyimide films. Since the incident IR beam is normal to the substrate, $\theta$ indicates the angle between transition moment and substrate. Larger $\left\langle\cos ^{2} \theta\right\rangle$ means the smaller angle $\theta$ between transition moment and substrate. $\left\langle\cos ^{2} \theta_{1375}\right\rangle$ is related to the in-plane orientation of the polyimide chain director. $\left\langle\cos ^{2} \theta_{1720}\right\rangle$ and $\left\langle\cos ^{2} \theta_{725}\right\rangle$ correspond to the parallel character of pyromellitimide ring to the substrate which changes by rotating the imide ring along the axis of chain direction. That the S-300 has shown the largest value of $\left\langle\cos ^{2} \theta_{1375}\right\rangle$ among the three polyimide films indicates that the S-300 has the higher in-plane orientation. This is expected to originate from the densely packed molecular alignment of the S-300 along the substrate. $\left\langle\cos ^{2} \theta_{1720}\right\rangle$ increased in the order: I-300<I-200<S300 , but $\left\langle\cos ^{2} \theta_{725}\right\rangle$ increased in the reversed order: $S$ $300<\mathrm{I}-200<\mathrm{I}-300$. The larger $\left\langle\cos ^{2} \theta_{1720}\right\rangle$ and the smaller $\left\langle\cos ^{2} \theta_{725}\right\rangle$, the more parallel alignment of the imide ring to the substrate. Therefore, the imide ring of the S-300 is most parallel to the substrate. Schematic illustration of molecular orientations describing these situations was given in Figure 6.

The behavior above seems to be dependent on the rate of chain immobilization during imidization. In the course of thermal imidization, the chains become more rigid and the solvents evaporate, which can cause increase in in-plane orientation. However, abrupt increase of the degree of imidization and rapid evaporation of the solvent also cause increase in $T_{\mathrm{g}}{ }^{4}$ When the $T_{\mathrm{g}}$ reaches the imidization temperature, the long range molecular

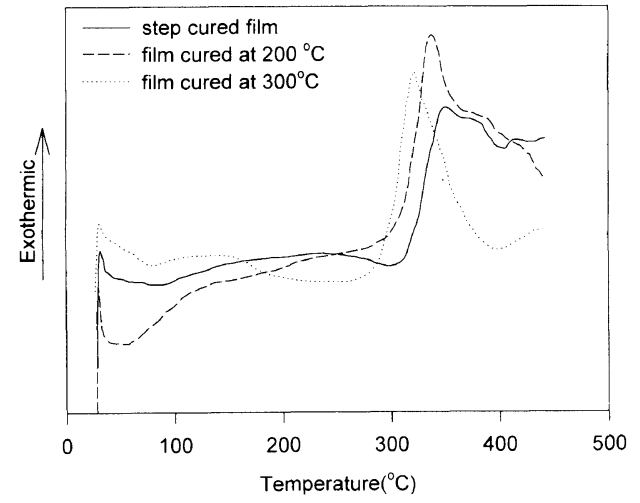

Figure 7. DSC thermograms of polyimide films measured during first heating.

arrangement, i.e., increase of in-plane orientation, becomes impossible. For the step curing, the unbound solvent evaporates and slight imidization occurs in the first step as shown in Figures 4 and 5. During this step, the chains can be packed more parallel to the substrate, because the immobilization rate of the chain is slow in this step. For the isothermal curing at $200^{\circ} \mathrm{C}$ and $300^{\circ} \mathrm{C}$, the imidization rate may be much higher than that of the step curing, and the chains are rapidly immobilized before considerable chain arrangement occurs. This results in lower in-plane orientation and less parallel alignment of imide ring to the substrate than the step cured film.

A comparison of molecular orientations between the I-200 and the I-300 supports our consideration. The I-200 showed higher in-plane orientation and greater parallel alignment of imide ring than the I-300. The slower immobilization rate at lower temperature provides longer time for chain rearrangement.

\section{Effects of Curing on Chain Ordering}

Figure 7 shows DSC thermograms of differently cured polyimide films measured during the first heating. Exothermic peaks are observed above $300^{\circ} \mathrm{C}$. Such an exothermic peak is known to arise from the chain ordering. ${ }^{1}$ Since the degradation of PMDA-ODA is normally observed above $500^{\circ} \mathrm{C},{ }^{17}$ these exothermic peaks cannot come from the degradation of polyimide. From Figure 7, it is found that the I-300 has the lowest onset temperature and S-300, the highest. This indicates that ease in chain ordering increases in the order: $\mathrm{S}$ $300<\mathrm{I}-200<\mathrm{I}-300$. Since the chain ordering involves diffusion of the chain, a sparsely packed chain should form the ordered phase more easily. Considering the order of increase in the in-plane orientation and parallel alignment of imide ring to the substrate, the chain packing should increase in the order: I-300 $<$ I- $200<\mathrm{S}$ 300 . For I-300, the exothermic peak diminished at $400^{\circ} \mathrm{C}$, whereas the I-200 and the S-300 revealed exothermic heat flow even above $400^{\circ} \mathrm{C}$. Some unordered region after the first heating of I-200 and S-300 thus remain. This means the ordering is not yet complete. Figure 8 shows the DSC thermograms of the second heating of the polymide films which were differently cured and underwent the first heating. In Figure 8, exothermic peaks were observed and associated with the chain ordering of 


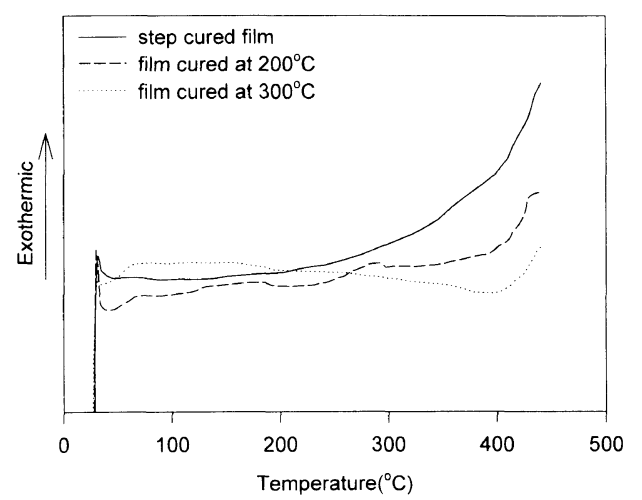

Figure 8. DSC thermograms of polyimide films measured during second heating.

the remaining unordered region. The heat of ordering for S-300 was largest among the three polyimide films, due to the remaining unordered part after the first heating. The order of onset point of ordering from the second heating was the reverse of that from the first heating. Larger amount of the remaining unordered part after the first heating caused the earlier onset of ordering and the larger exothermic heat flow at the second heating.

Acknowledgment. The authors thank the Functional Polymer Engineering Research Center for supporting this work.

\section{REFERENCES}

1. M. K. Ghosh and K. L. Mittal, Ed., "Polyimides: Fundamentals and Applications," Marcel Dekker, New York, N.Y. 1996.

2. M. I. Bessonov and V. A. Zubkov, Ed., "Polyamic Acids and Polyimide: Synthesis, Transformation, and Structure," CRC Press, Boca Raton, Florida, 1993.

3. P. D. Frayer, in "Polyimides," Vol. 1, K. L. Mittal, Ed., Pleum Press, New York, N.Y., 1984, p 273.

4. S. Numata, K. Fujisaki, and N. Kinjo, in "Polyimides," Vol. 1, K. L. Mittal, Ed., Pleum Press, New York, N.Y., 1984, p 254.

5. P. Sysel, V. Konecna, and K. Volka, Eur. Polym. J., 32, 317 (1996).

6. K. Iida, Y. Imamura, C. Liao, S. Nakamura, and G. Sawa, Polym. J., 28, 352 (1996)

7. R. R. Cheng and S. L. Wunder, J. Polym. Sci., Part B, 34, 435 (1996).

8. J.-H. Jou and P.-T. Huang, Macromolecules, 24, 3796 (1991).

9. H. Ishida and M. T. Huang, J. Polym. Sci., Part B, 32, 2271 (1994).

10. C. A. Pryde, J. Polym. Sci., Part A, 27, 711 (1989).

11. J. R. Ojeda, J. Mobley, and D. C. Martin, J. Polym. Sci., Part $B, 32,559$ (1994).

12. N. Takahashi, Do Y. Yoon, and W. Parrish, Macromolecules, 17, 2583 (1984)

13. S. F. Tead and E. J. Kramer, Polymer, 31, 520 (1990).

14. R. W. Snyder, C. W. Sheen, and C. P. Painter, Appl. Spectrosc., 42, 503 (1988)

15. B. Thomson, Y. Park, and P. C. Painter, Macromolecules, 22 , 4159 (1989).

16. J. L. Koenig, S. W. Cornell, and D. E. Witenhafer, J. Polym. Sci., A2, 301 (1967).

17. M. Navarre, in "Polyimides," Vol. 1, K. M. Mittal, Ed., Pleum Press, New York, N.Y., 1984, p 429.

18. J. A. Kreuz, A. L. Endrey, F. P. Gay, and C. E. Sroog, J. Polym. Sci., A-1, 4, 2607 (1960).

19. L. A. Laius, M. I. Bessonov, Ye. V. Kallistova, N. A. Adrova, and F. S. Florinskii, Polym. Sci. USSR, A9, 2470 (1967).

20. M. M. Koton, T. K. Meleshko, V. V. Kudryavtsev, P. P. Nechayev, Ye. V. Kamzolkina, and N. N. Bogorad, Polym. Sci. USSR, A24, 791 (1982). 